\title{
The Effect of Wood Extract as a Water-Soluble Fertilizer in the Growth of Lactuca sativa ${ }^{1}$
}

\author{
Ji Young $\mathrm{JUNG}^{2} \cdot \mathrm{Si}$ Young $\mathrm{HA}^{2,3} \cdot$ Jae-Kyung YANG (D) ${ }^{2,3, \dagger}$
}

\begin{abstract}
Recently, due to environmental and toxicity issues, there has been increasing attention on research regarding natural products that can reduce the use of chemical fertilizers. Wood extracts derived from the biorefining process contain various fertilizer ingredients. HPLC analysis revealed that wood extract contains approximately $5.2 \%$ hemicellulosic sugar. The growth of lettuce (Lactuca sativa) upon treatment with wood extract (extract obtained from steam-exploded pine) or water-soluble fertilizers containing different nutrients was analyzed in this study. After two weeks, the growth characteristics of lettuce as affected by wood extract or water-soluble fertilizers were significantly different. The effect of water-soluble fertilizers containing ascorbic acid, magnesium sulfate, citric acid, potassium nitrate, amino acids, or seaweed extract was less desirable than that of wood extracts regarding plant height $(18.6 \mathrm{~cm})$, number of leaves $(10)$, leaf length $(14.1 \mathrm{~cm})$, shoot fresh wight $(9.8 \mathrm{~g} / \mathrm{plant})$, root fresh weight $(0.8 \mathrm{~g} /$ plant $)$ and shoot dry weight $(0.6 \mathrm{~g} /$ plant). The plant height, number of leaves, leaf length, shoot fresh wight, root fresh weight, shoot dry weight of water-soluble fertilizers containing wood extract were significantly different compared to the control (plant height :13.5 cm, number of leaves : 7, leaf length : $9.4 \mathrm{~cm}$, shoot fresh wight : $5.3 \mathrm{~g} / \mathrm{plant}$, root fresh weight : $0.7 \mathrm{~g} / \mathrm{plant}$, shoot dry weight : $0.4 \mathrm{~g} /$ plant, root dry weight : $0.07 \mathrm{~g} / \mathrm{plant}$ ). From these results, it was concluded that wood extract can be used as a potential water-soluble fertilizer to increase the yield of leafy vegetables.
\end{abstract}

Keywords: Pinus densiflora, steam explosion, wood extract, water-soluble fertilizer, Lactuca sativa

\section{INTRODUCTION}

Biorefinery processes involve the use of a renewable carbon source to minimize the amount of waste generated, or even to exploit industrial residues. The biorefinery concept has emerged in recent years, with the aim of developing integrated processes for the conversion of biomass into energy and a variety of products, mainly biofuels and value-added by-products, in a sustainable manner (Cherubini, 2010). Many types of lignocellulosic biomass can be utilized as raw materials in a biorefinery, including softwoods, hardwoods, and herbaceous materials such as energy crops and agricultural residues (Cai et al., 2017; Lee et al., 2019).

In a biorefinery, pretreatment is required to separate the components of lignocellulosic biomass (Alvira et al., 2010; Kim et al., 2019; Kim et al., 2015). Steam explosion pretreatment is a simple, low-cost, and environmentally friendly technology that causes the depolymerization of hemicellulose into soluble oligomers

\footnotetext{
${ }^{1}$ Date Received May 6, 2021, Date Accepted July 12, 2021

${ }^{2}$ Institute of Agriculture and Life Sciences, Gyeongsang National University, Jinju 52828, Republic of Korea

${ }^{3}$ Department of Environmental Materials Science, Gyeongsang National University, Jinju 52828, Republic of Korea

$\dagger$ Corresponding author: Jae-Kyung YANG (e-mail: jkyang68@gmail.com, ORCID: 0000-0003-0423-6398 )
} 
The Effect of Wood Extract as a Water-Soluble Fertilizer in the Growth of Lactuca sativa

and their transformation to lignin, taking advantage of its high temperature profile (Li et al., 2007; Jung and Yang, 2016). During steam explosion, some of the lignocellulosic biomass becomes solubilized as polymers or monomers, while the other parts become degraded or transformed into new components. However, studies on the steam explosion of lignocelluloses have mainly focused on their lignin and cellulose fractions. While the processes regarding the fractionation of biomass into an isolated, solid, cellulose-rich fraction and a lignin-rich fraction are well understood, the isolation of heteropolysaccharides in polymeric forms, which are useful in a variety of polymer applications, has not yet been addressed in relation to steam explosion (Sun et al., 2002).

Water-soluble fertilizers are a special class of fertilizers that hold promise in applications such as protected cultivation, hydroponics/aeroponics, or even open field hydroponics for perennial fruit crops. In addition, water-soluble fertilizers are used in sprinkler or drip irrigation systems and for foliar spraying to increase the yield and improve the quality of fruit and vegetable crops (Malhotra, 2016). Water-soluble fertilizers provide an enormous possibility of tailoring nutrient use across critical growth stages, a prerequisite for better nutrient use efficiency. These are mostly combinations of nitrogen, phosphorus, potassium, calcium, magnesium, sulfur, and other micronutrients at different ratios (Rajput and Patel, 2002). Modern agriculture is searching for new biotechnologies that would allow for a reduction in chemical inputs without negatively affecting crop yield or farmers' incomes.

During the manufacture of sugar, molasses is a by-product that is left after most of the sugar from sugar cane or sugar beets has been extracted. It increases the shoot length, leaf number per plant, leaf area, and chlorophyll content of peas. The sugar content in dry molasses also increases microbial activity, which, in turn, increases the availability of micro- nutrients to plants and encourages the growth of beneficial microorganisms. Molasses can be easily added to scores of organic liquid fertilizers such as kelp, alfalfa meal tea, and compost tea to give plants the necessary carbohydrates they need (Shirgure and Srivastava, 2014; Shehata et al., 2011).

The softwood, such as pine contain a large amount of hemicellulose. Also, pine is one of the major plantation tree species in the Republic of Korea (Lee et al., 2020; Min et al., 2019; Jung et al., 2019). It is considered that the liquid fraction containing hemicellulosic sugar (Jung and Yang, 2018), such as molasses, generated during the pretreatment stage in a biorefinery can serve as a fertilizer. Lettuce (Lactuca sativa) is one of the most important vegetables in the world, and is the main crop in plant factories (Nicolle et al., 2004, Dupont et al., 2000). Therefore, the present study aimed to determine the effect of using steam-exploded pine extract as a water-soluble fertilizer for the growth of Lactuca sativa. All data obtained during this study were evaluated via principal component analysis (PCA) for the growth of Lactuca sativa using water-soluble fertilizer.

\section{MATERIALS and METHODS}

\subsection{Preparation of wood extract}

Pine (Pinus densiflora) was collected from the experimental forest of Gyeongsang National University, Jinju, South Korea. The pine was chipped to a particle size of approximately $2 \times 2 \times 0.5 \mathrm{~cm}^{3}$ for steam explosion and stored at $20^{\circ} \mathrm{C}$ at a moisture level below $10 \%-15 \%$.

The chipped raw material was then exploded with steam (severity factor $[R o]=3.86,197^{\circ} \mathrm{C}, 10 \mathrm{~min}$ ) to maximize the soluble carbohydrate content. The severity factor $(R o)$ was calculated using the following equation (De Bari et al., 2002): Severity $\log (R o)=$ 
$\log [t \times \exp (T-100 / 14.75)]$, where $t$ is the residence time in minutes, and $T$ is the reaction temperature in ${ }^{\circ} \mathrm{C}$. Then, hot water extraction $\left(90^{\circ} \mathrm{C}, 120 \mathrm{~min}, 1 / 39[\mathrm{w} / \mathrm{v}]\right)$ was carried out to extract (Jung and Yang, 2018) low molecular weight carbohydrates. Consequently, filtration was conducted for further refinement.

\subsection{Preparation of water-soluble fertilizer}

Water-soluble fertilizer was prepared by mixing the wood extract with commercially available nutrients. Commercially available nutrients included ascorbic acid (F1), magnesium sulfate (F2), citric acid (F3), potassium nitrate (F4), amino acid (F5), and seaweed extract (F6). Water was used as a control (DW). The ratios of each formulation to each nutrient solution are shown in Table 1.

\subsection{Pot experiment}

The plant material used to evaluate the suitability of the nutrient solution as a growth enhancer was lettuce (Lactuca sativa). Lettuce seeds were surface sterilized via immersion in $10 \%$ sodium hypochlorite solution for $10 \mathrm{~min}$, rinsed three times with deionized water, soaked in deionized water for $2 \mathrm{~h}$, and finally sown in the prepared mixture substrate.

In the pot experiment, after filling the growing media (peatmoss, perlite, vermiculite) in a 105 -cell plug tray, 1 to 2 seeds per cell were sown and seeded for 14 to 18 days. Upon the appearance of three to four leaves, the same growing medium was filled in a cylindrical plastic container with a diameter of $10 \mathrm{~cm}$ and a height of $8 \mathrm{~cm}$, then the plants were transplanted one by one into these containers. To these, $20 \mathrm{~mL}$ of the wood extract (formulations 1 to 6) were supplied every day (the control was supplied with water only). The average temperatures during the day and night were $30^{\circ} \mathrm{C}$ and $18^{\circ} \mathrm{C}$, respectively. The relative humidity was $37.1 \%-61.2 \%$ during the growth period. According to the plant water requirements, irrigation was performed one to three times per day. After sample collection at 2 weeks, a growth test (five repetitions, total number of samples $=80$ ) was performed. Three heads were randomly selected from each variety during harvest. Different aspects of plant growth were determined, including plant height, number of leaves, leaf length, SPAD value (leaf chlorophyll), shoot fresh weight, root fresh weight, shoot dry weight, and root dry weight, and were measured at the end of the growth period.

Table 1. Water-soluble fertilizers used in this study

\begin{tabular}{ccccccccc}
\hline Material & \multicolumn{1}{c}{ Formulation, \% } \\
\cline { 2 - 8 } & $\mathrm{DW}^{1)}$ & Wood extract & F1 & F2 & F3 & F4 & F5 & F6 \\
\hline \hline Water & 100 & 50 & 99 & 99 & 99 & 99 & 99 & 99 \\
Wood extract & - & $50(15)^{2)}$ & - & - & - & - & - & - \\
Ascorbic acid & - & - & $1(10)$ & - & - & - & - & - \\
Magnesium sulfate & - & - & - & $1(10)$ & - & - & - & - \\
Citric acid & - & - & - & - & $1(10)$ & - & - & - \\
Potassium nitrate & - & - & - & - & - & $1(10)$ & - & - \\
Amino acid & - & - & - & - & - & - & $1(10)$ & - \\
Seaweed extract & - & - & - & - & - & - & - & $1(10)$ \\
\hline
\end{tabular}

${ }^{1)}$ Control

${ }^{2)}$ Data are expressed in parentheses as a weight of solid content $(\mathrm{g} / \mathrm{L})$ 
The plant height was measured using Vernier calipers (Mitutoyo, model 500-144B, Tokio, Japan), from the ground to the apex of the plastic container in which the plants were planted (Lee et al., 2013).

The number of leaves that was $1 \mathrm{~cm}$ or more were counted. Leaf length was measured using the third to fourth largest leaf from the top (Kim et al., 2005).

SPAD measurements were performed using a SPAD-502 chlorophyll meter (Minolta Co. Ltd., Osaka, Japan). Measurements were taken using the flag leaves of five randomly selected plants within each plot. For each plant, the average of three SPAD readings around the midpoint of the flag leaves was taken.

The fresh weight and dry weight of lettuce separated by the shoots and roots were measured with an electronic scale (model SBA 51; Scaltec Instruments, Goettingen, Germany). The shoots and roots used for the measurement of dry weight were dried for 3 days in an oven maintained at a temperature of $70^{\circ} \mathrm{C}$ (OF-22GW, Jeio Tech, Seoul, Korea).

\subsection{Analysis of carbohydrate}

The carbohydrate composition of the wood extract was determined by the National Renewable Energy Laboratory (NREL) using standard biomass analytical procedures (Sluiter et al., 2005). The arabinose, xylose, mannose, galactose, and glucose levels were determined using high-performance liquid chromatography (HPLC). The HPLC (Agilent, USA) system used was equipped with an Aminex HPX-87P column (Bio-Rad, Hercules, CA), a guard column, an automated sampler, a gradient pump, and a refractive index detector. The mobile phase was deionized water at a flow rate of $0.6 \mathrm{~mL} / \mathrm{min}$ at $85^{\circ} \mathrm{C}$. Prior to HPLC injection, all samples were neutralized with calcium carbonate and filtered through $0.2-\mu \mathrm{m}$ syringe filters.

\subsection{Statistical Analysis}

All experiments were performed in triplicates. Data were analyzed using SAS statistical software, and Duncan's multiple range test was used for the comparison of treatment means when P-values were significant at $\mathrm{P}<0.05$. The correlation between water-soluble fertilizer and growth was established via principal component analysis (PCA) using JMP software (version 16; SAS Institute).

\section{RESULTS and DISCUSSION}

\subsection{Carbohydrate composition of wood extract}

The major biomass constituents, including hemicellulose, cellulose, and lignin, were relatively sensitive to the treatment temperature. At approximately $200^{\circ} \mathrm{C}$, hemicellulose and lignin started to degrade; macromolecules of the hemicelluloses started to decompose to their corresponding oligomeric fragments, then short chains are depolymerized to monomer units and subsequently decomposed to volatiles, but only to a small extent (Shoulaifar et al., 2014).

The carbohydrate compositions of the wood extracts used in this study are presented in Table 2. The wood extracts contained carbohydrates. Based on HPLC carbohydrate analysis, the sugar fraction was $16.5 \%$ of the dry biomass. Mannose, the major hemicellulose

Table 2. Carbohydrate composition of the wood extract obtained from steam-exploded pine

\begin{tabular}{cc}
\hline Composition & $\mathrm{g} / 100 \mathrm{~g}$ raw material \\
\hline \hline Carbohydrate & \\
Arabinose & 0.5 \\
Xylose & 2.1 \\
Mannose & 7.9 \\
Galactose & 2.3 \\
Glucose & 3.7 \\
\hline
\end{tabular}


constituent, accounted for $7.9 \%$. Arabinose $(0.5 \%)$, xylose $(2.1 \%)$ and galactose $(2.3 \%)$, and accounted for a small portion of the biomass. Glucose, which was derived from both the pinewood fiber and plant cell wall, was $3.7 \%$. The wood extract obtained from steam-exploded pine $\left(197^{\circ} \mathrm{C}, 10 \mathrm{~min}\right)$ was mainly composed of hemicellulose sugar (xylose, mannose, galactose, and arabinose). Also, the $\mathrm{pH}$ of wood extract was about 5.7.

\subsection{Effect of water-soluble fertilizer on growth of lettuce}

\subsubsection{Plant height}

The effects of wood extract or wood extract with some nutrients on the changes in plant height were investigated (Fig. 1). Significant differences in leaf area were observed among the eight treatments (DW, wood extract, F1, F2, F3, F4, F5, and F6). It is worth mentioning that the application of steam-exploded pine extract either alone or with ascorbic acid, magne-

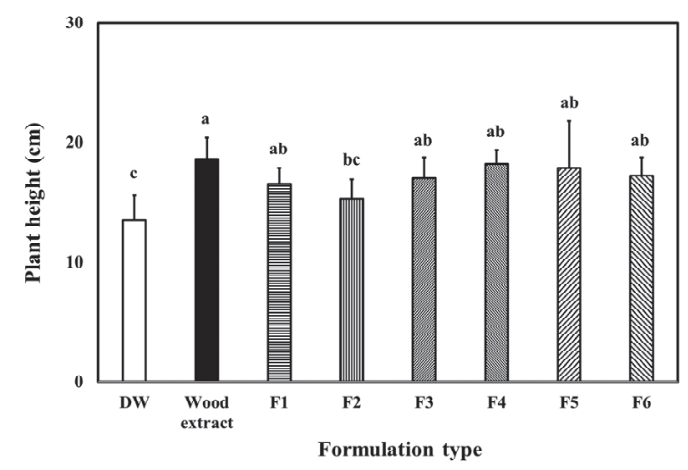

Fig. 1. Plant height of Lactuca sativa grown in DW (control; top water, without nutrients), wood extract (50\% steam-exploded pine extract), F1 (1\% ascorbic acid), F2 (1\% magnesium sulfate), F3 (1\% citric acid), F4 ( $1 \%$ potassium nitrate), F5 ( $1 \%$ amino acids), F6 ( $1 \%$ seaweed extract) for two weeks. Vertical bars represent the standard error of the mean. The values indicated in different letters are significantly different compared to other values. sium sulfate, citric acid, potassium nitrate, amino acid, or seaweed extract significantly increased the plant height compared with the control (DW; $13.5 \mathrm{~cm})$. The setups treated with pine extract alone showed the highest plant height $(18.6 \mathrm{~cm})$. Among the treatments F1, F2, F3, F4, F5, and F6, in which nutrients were added to water, F2 (containing magnesium sulfate) showed the lowest plant height $(15.3 \mathrm{~cm})$. There were no significant differences in the plant heights in the F1$(16.5 \mathrm{~cm})$, F3- $(17.0 \mathrm{~cm})$, F4- $(18.2 \mathrm{~cm})$, F5- $(17.9$ $\mathrm{cm})$, and F6- $(17.2 \mathrm{~cm})$ treated samples.

\subsubsection{Number of leaves}

Fig. 2 shows the changes in the number of lettuce leaves upon the addition of pine extract and some nutrients. Water-soluble fertilizers significantly affected leaf number, and the highest leaf numbers were found in the plants treated with wood extract (10), F3 (10), F4 (10), and F5 (10), while the DW-treated samples had the least number of leaves (control; 7). No

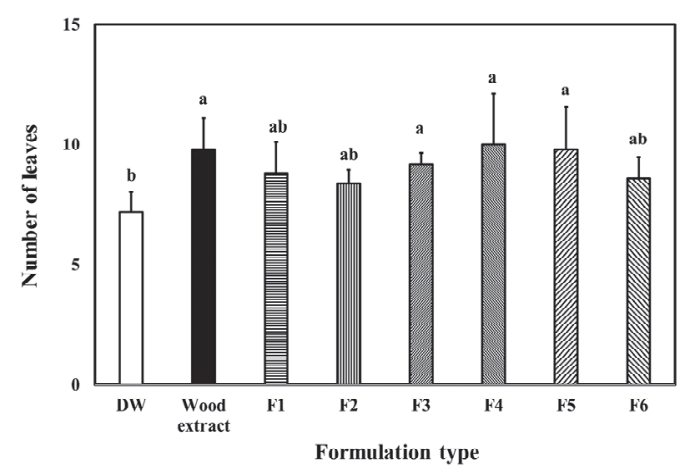

Fig. 2. Number of leaves of Lactuca sativa grown in DW (control; top water, without nutrients), wood extract (50\% steam-exploded pine extract), F1 (1\% ascorbic acid), F2 (1\% magnesium sulfate), F3 (1\% citric acid), F4 (1\% potassium nitrate), F5 (1\% amino acids), F6 (1\% seaweed extract) for two weeks. Vertical bars represent the standard error of the mean. The values indicated in different letters are significantly different compared to other values. 
significant differences in leaf number were found between F1 (9), F2 (8), and F6 (9).

\subsubsection{Leaf length}

The wood extract, nutrients, and their interactions exhibited a prominent effect on lettuce leaf length (Fig. 3). Maximum leaf length was observed in the plants treated with wood extract $(14.1 \mathrm{~cm})$ and $\mathrm{F} 5$ $(13.6 \mathrm{~cm})$.

\subsubsection{SPAD value}

SPAD-502 (Minolta Ltd., Osaka, Japan) is a handheld chlorophyll meter that indirectly determines leaf chlorophyll content. It measures the leaf transmittance in red light at $650 \mathrm{~nm}$ (at which chlorophyll absorbs) and in near-infrared light at $940 \mathrm{~nm}$ (for the correction of leaf thickness). The ratio of these two transmission values is referred to as the SPAD (Soil Plant Analysis Development) reading or SPAD value (Hoel and Solhaug, 1998). A decrease in the SPAD value in-

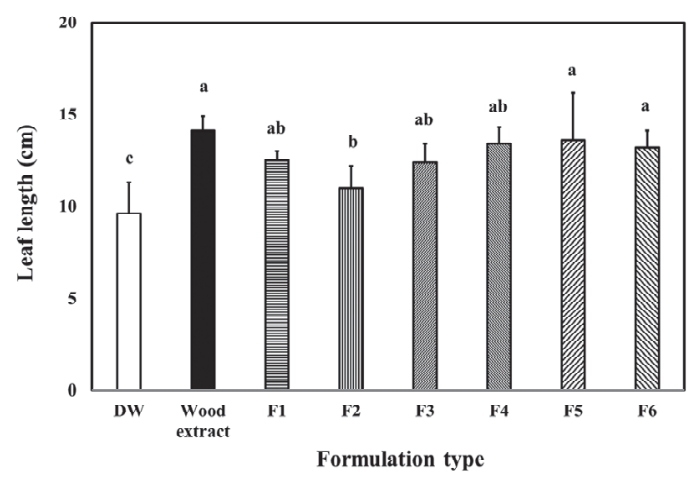

Fig. 3. Leaf length of Lactuca sativa grown in DW (control; top water, without nutrients), wood extract (50\% steam-exploded pine extract), F1 (1\% ascorbic acid), F2 (1\% magnesium sulfate), F3 ( $1 \%$ citric acid), F4 (1\% potassium nitrate), F5 (1\% amino acids), F6 (1\% seaweed extract) for two weeks. Vertical bars represent the standard error of the mean. The values indicated in different letters are significantly different compared to other values. dicates an increase in the red color of the Lactuca sativa used. The SPAD values of the wood extract, F1, F2, F3, F4, F5, and F6 treatments ranged from 14.0 to 18.1 , while that of DW was 17.8 . While there were numerical differences in SPAD values, they were not significant $(\mathrm{P}>0.05)$.

\subsubsection{Fresh weight and dry weight}

The resulting fresh and dry weights of lettuce upon the application of water-soluble fertilizers are shown in Fig. 5 and 6. Fig. 5 shows the fresh weights of lettuce by dividing them into shoots (Fig. 5(a)) and roots (Fig. 5(b)). The fresh weight of shoots was highest in the lettuce treated with wood extract $(9.8$ $\mathrm{g} /$ plant) and F5 (7.4 g/plant). The fresh weights of lettuce treated with F1 (6.5 g/plant), F2 (4.8 g/plant), F3 (7.0 g/plant), F4 (6.6 g/plant), and F6 (5.5 g/plant) were higher than that of the control ( $5.3 \mathrm{~g} /$ plant), but there was no statistically significant difference between them. On the other hand, the fresh weight of

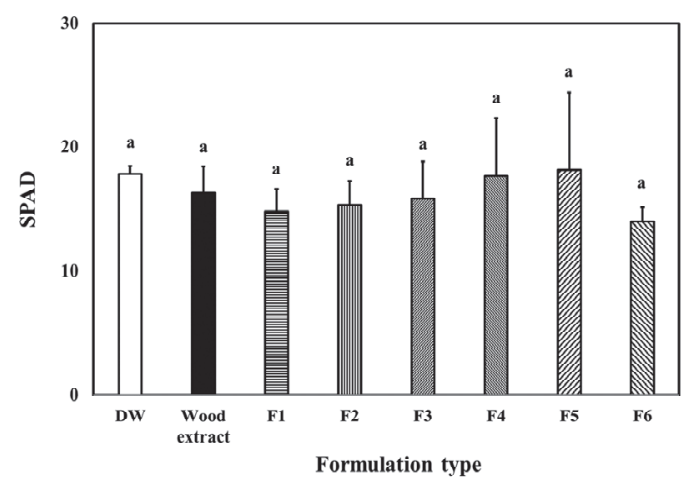

Fig. 4. SPAD value of Lactuca sativa grown in DW (control; top water, without nutrients), wood extract (50\% steam-exploded pine extract), F1 (1\% ascorbic acid), F2 (1\% magnesium sulfate), F3 (1\% citric acid), F4 (1\% potassium nitrate), F5 (1\% amino acids), F6 (1\% seaweed extract) for two weeks. Vertical bars represent the standard error of the mean. The values indicated in different letters are significantly different compared to other values. 
the roots was reduced in the lettuce treated with F1 (0.5 g/plant), F2 (0.4 g/plant), F3 (0.5 g/plant), F4 (0.3 g/plant), F5 (0.4 g/plant), and F6 (0.2 g/plant), compared to the control $(0.7 \mathrm{~g}$ /plant $)$; however, the fresh weight of lettuce treated with wood extract $(0.8$ g/plant) increased. Fig. 6 shows the dry weight of the shoots (Fig. 6(a)) and roots (Fig. 6(b)) of lettuce to which different water-soluble fertilizers were applied. The dry weight of the shoot was higher in the lettuce treated with wood extract $(0.6 \mathrm{~g} /$ plant $)$ and F5 (0.5 $\mathrm{g} /$ plant), while the dry weights of the lettuce treated with F1 (0.4 g/plant), F2 (0.3 g/plant) and F6 (0.3 $\mathrm{g} /$ plant) were lower than that of the control ( 0.4 $\mathrm{g} /$ plant). The dry weight of lettuce roots to which other
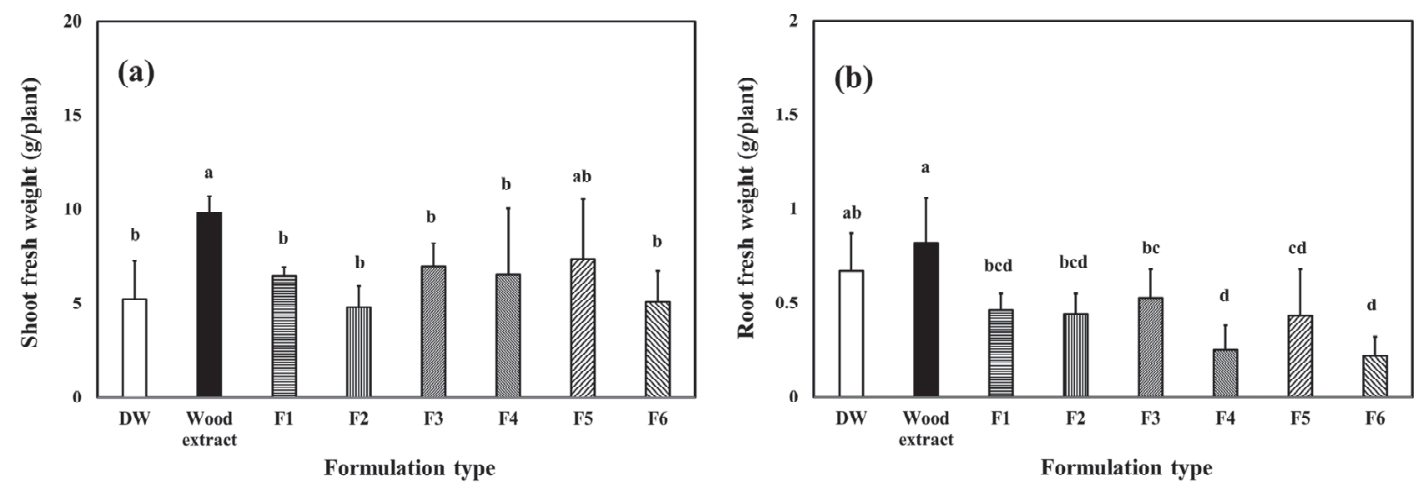

Fig. 5. Root and shoot fresh weight of Lactuca sativa grown in DW (control; top water, without nutrients), wood extract (50\% steam-exploded pine extract), F1 (1\% ascorbic acid), F2 (1\% magnesium sulfate), F3 ( $1 \%$ citric acid), F4 (1\% potassium nitrate), F5 (1\% amino acids), F6 (1\% seaweed extract) for two weeks. Vertical bars represent the standard error of the mean. The values indicated in different letters are significantly different compared to other values.
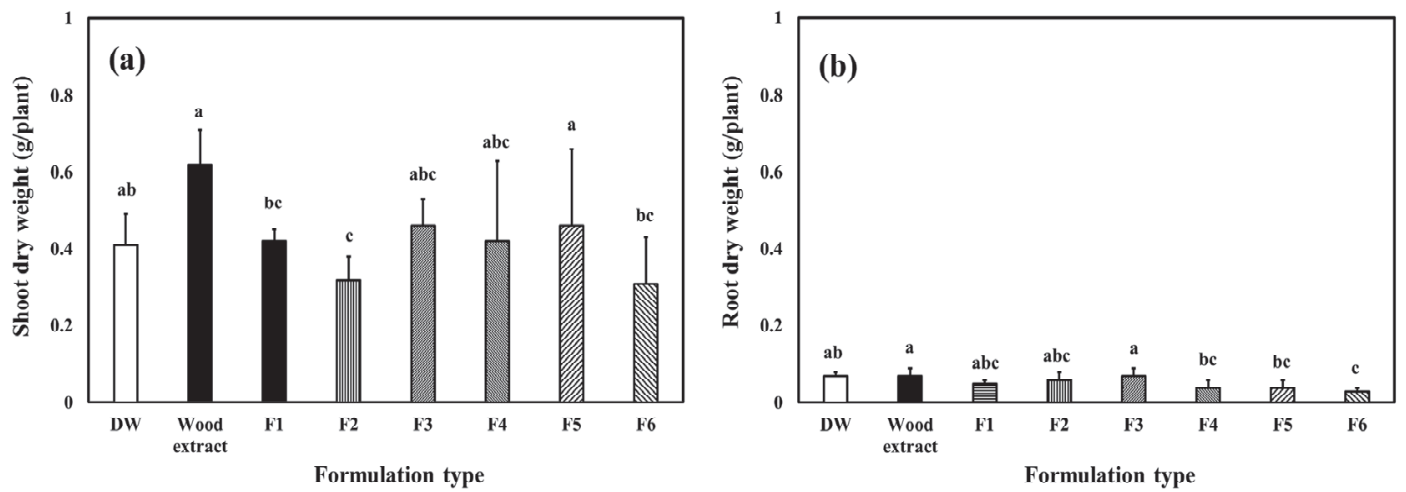

Fig. 6. Root and shoot dry weight of Lactuca sativa grown in DW (control; top water, without nutrients), wood extract ( $50 \%$ steam-exploded pine extract F1 (1\% ascorbic acid), F2 (1\% magnesium sulfate), F3 (1\% citric acid), F4 (1\% potassium nitrate), F5 (1\% amino acids), F6 (1\% seaweed extract) for two weeks. Vertical bars represent the standard error of the mean. The values indicated in different letters are significantly different compared to other values. 
The Effect of Wood Extract as a Water-Soluble Fertilizer in the Growth of Lactuca sativa

types of water-soluble fertilizers were applied showed a small value, in the range of $0.03 \mathrm{~g} /$ plant to 0.07 $\mathrm{g} /$ plant, and were not significantly different compared to the control $(0.07 \mathrm{~g} /$ plant $)$.

\subsection{Correlation between water-soluble fertilizer and growth of Lactuca sativa}

The relationship between water-soluble fertilizers, (DW [control], wood extract, F1, F2, F3, F4, F5, and F6) and the growth of Lactuca sativa was determined via principal component analysis (PCA) (Fig. 7). A set of seven principal components was generated using PCA. The first principal component had the highest eigenvalue (4.1) and accounted for $50.7 \%$ of the variability in the data set. The second had an eigenvalue of 2.9 , accounting for $35.7 \%$ of the variance in the data. Only principal components 1 and 2, which have

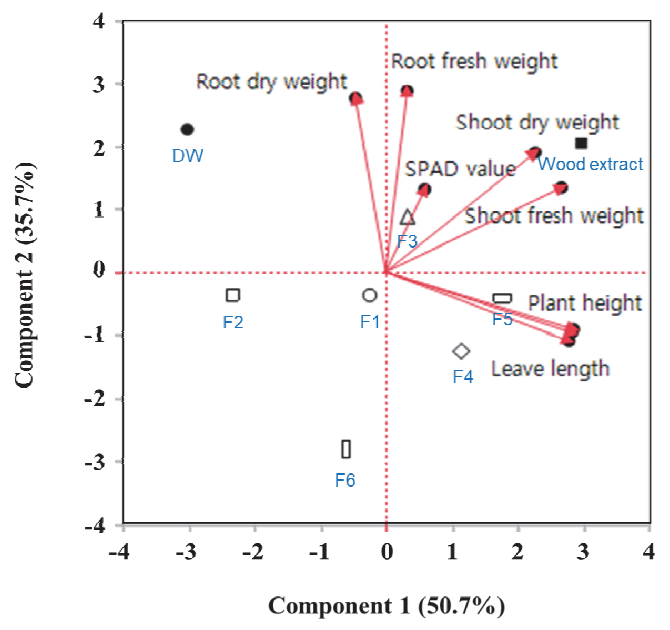

Fig. 7. Correlation between the use of water-soluble fertilizer and the growth of Lactuca sativa as determined via principal component analysis. DW: top water (control); wood extract: 50\% steam-exploded pine extract; F1: 1\% ascorbic acid; F2: 1\% magnesium sulfate; F3: $1 \%$ citric acid; F4: $1 \%$ potassium nitrate; F5: $1 \%$ amino acid; F6: $1 \%$ seaweed extract. eigenvalues higher than 1.0, were considered significant descriptors of data variance in this study according to Kaiser's rule. Principal components 1 and 2 explained $86.4 \%$ of the observed effects. Treatment with wood extract was positively correlated with SPAD value, root fresh weight, shoot fresh weight, and shoot dry weight. The hemicellulosic sugar contained in the wood extract was considered to have an effect on the growth of lettuce (Table 1). Yi et al. (2019) reported that wood-derived biochar amendment increased yield of Lettuce as well as improving soil properties. Noh et al. (2020) reported that the growth of lettuce was decreased due to the reactive oxygen species such as ozone in the plasma-activated water, but the secondary metabolites in the root zone increased significantly. The wood-derived extract is considered to have potential as an alternative source of water-soluble fertilizers for the growth of lettuce.

\section{CONCLUSION}

The application of wood extract influenced the growth characteristics of lettuce. Our experimental results show that providing lettuce with water-soluble fertilizers has beneficial effects in plant height, number of leaves, leaf length, shoot fresh weight, root fresh weight, and shoot dry weight. Application of wood extract did not show significantly positive effects in SPAD value and shoot dry weight. PCA analysis showed that wood extract was positively correlated with SPAD value, root fresh weight, shoot fresh weight, and shoot dry weight. This was considered to be related to the hemicellulose sugar content in the wood extract. Overall, these results indicate the possibility of using extracts as water-soluble fertilizers, and further studies on the relationship between hemicellulosic sugar and the growth characteristics of plants should be conducted in the future. 


\section{ACKNOWLEDGMENT}

This research was supported by Basic Science Research Program through the National Research Foundation of Korea (NRF) funded by the Ministry of Education (No. 2018R1D1A1A02045243).

\section{REFERENCES}

Alvira, P., Tomás-Pejó, E., Ballesteros, M., Negro, M.J. 2010. Pretreatment technologies for an efficient bioethanol production process based on enzymatic hydrolysis: A review. Bioresource Technology 101(13):4851-4861.

Cai, J., He, Y., Yu, X., Banks, S.W., Yang, Y., Zhang, X., Yu, Y., Liu, R., Bridgwaterb, A.V. 2017. Review of physicochemical properties and analytical characterization of lignocellulosic biomass. Renewable and Sustainable Energy Reviews 76:309-322.

Cherubini, F. 2010. The biorefinery concept: Using biomass instead of oil for producing energy and chemicals. Energy Conversion and Management 51(7): 1412-1421.

De Bari, I., Viola, E., Barisano, D., Cardinale, M., Nanna, F., Zimbardi, F., Cardinale, G., Braccio, G. 2002. Ethanol production at flask and pilot scale from concentrated slurries of steam exploded aspen. Industrial and Engineering Chemistry Research 41(7): 1745-1753.

Dupont, M.S., Mondi, Z., Willamson, G., Price, K.R. 2000. Effect of variety, processing, and storage on the flavonoid glycoside and composition of lettuce and endive. Journal of Agricultural and Food Chemistry 48(9): 3957-3964.

Hoel, B.O., Solhaug, K.A. 1998. Effect of irradiance on chlorophyll estimation with the Minolta SPAD-502 leaf chlorophyll meter. Annals of Botany 82(3): 389-392.
Jung, J.Y., Yang, J.K. 2016. Enhancing enzymatic digestibility of Miscanthus sinensis using steam explosion coupled with chemicals. Journal of the Korean Wood Science and Technology 44(2): 218-230.

Jung, J.Y., Yang, J.K. 2018. A two-stage process for increasing the yield of prebiotic-rich extract from Pinus densiflora. Journal of the Korean Wood Science and Technology 46(4): 380-392.

Jung, J.Y., Yang, Ha, S.Y., Yang, J.K. 2019. Effect of water-impregnation on steam explosion of Pinus densiflora. Journal of the Korean Wood Science and Technology 47(2): 189-199.

Kim, H.Y., Gwak, K.S., Jang, S.K., Ryu, K.O., Yeo, H.M., Choi, I.G. 2015. Organosolv pretreatment of slurry composting and biofiltration of liquid fertilizer-treated yellow poplar for sugar production. Journal of the Korean Wood Science and Technology 43(5): 578-590.

Kim, I.S., Kim, S.J., Lee, J.Y., Lee, J.S. 2005. The effect of vermicast on the growth of vegetable plants-estimation of optimum mixture ratios of vermicast. Korean Journal of Organic Agriculture 13(4): 413-422.

Kim, J.S., Jung, J.Y., Ha, S.Y., Yang, J.K. 2019. Effects of the physicochemical properties of lignocellulosic artificial soil containing Bacillus subtilis on the growth of Lespedeza cyrtobotrya. Journal of the Korean Wood Science and Technology 47(4): 393-407.

Lee, H.W., Jeong, H.S., Ju, Y.M., Youe, W.J., Lee, J.J., Lee, S.M. 2019. Pyrolysis properties of lignins extracted from different biorefinery processes. Journal of the Korean Wood Science and Technology 47(4): 486-497.

Lee, M., Jeong, S.H., Mun, S.P. 2020. Conditions for the extraction of polyphenols from Radiata Pine (Pinus radiata) bark for bio-Foam preparation. Journal of the Korean Wood Science and 
Technology 48(6): 861-868.

Lee, S.Y., Kim, W.T., Ju, J.H., Yoon, Y.H. 2013. Effect of Calcium Chloride Concentration on Roadside Ground Cover Plant Growth. Journal of Korean Institute of Landscape Architecture 41(4): 17-23.

Li, J., Henriksson, G., Gellerstedt. 2007. Lignin depolymerization/repolymerization and its critical role for delignification of aspen wood by steam explosion. Bioresource Technology 98(16): 3061-3068.

Malhotra, S.K. 2016. Water soluble fertilizers in horticultural crops-An appraisal. Indian Journal of Agricultural Sciences 86(10): 1245-56.

Min, H.J., Kim, E.J., Shinn, S.W., Bae, Y.S. 2019. Antidiabetic Activities of Korean Red Pine (Pinus densiflora) Inner Bark Extracts. Journal of the Korean Wood Science and Technology 47(4): 498-508.

Nicolle, C., Carnat, A., Fraisse, D., Lamaison, J.L., Rock, E., Michel. H., Amouroux, P., Remesy, C. 2004. Characterisation and variation of antioxidant micronutrients in lettuce (Lactuca sativa folium). Journal of the Science of Food and Agriculture 84(15): 2061-2069

Noh, S.W., Park, J.S., Kim, S.J., Kim, D.W., Kang, W.S. 2020. Effect of Plasma-activated water Process on the growth and functional substance content of Lettuce during the cultivation period in a deep flow technique system. Protected Horticulture and Plant Factory 29(4): 464-472.

Rajput, T.B.S., Patel, N. 2002. Water Soluble FertilizersOpportunities and Challenges. FAI Annual seminar,
December 2002 pp. SII-3/1-9.

Shehata, S.M., Abdel-Azem, Heba.S., Abou El-Yazied, A., El-Gizawy, A.M. 2011. Effect of foliar spraying with amino acids and seaweed extract on growth chemical constitutes, yield and its quality of celeriac plant. European Journal of Scientific Research 58(2): 257-265.

Shirgure, P.S., Srivastava, A.K. 2014. Fertigation in perennial fruit crops: Major concerns. Agrotechnol 3(1): http://dx.dol.org/10.4172/2168-9881.1000e109 (Editorial).

Shoulaifar, K.T., DeMartini, N., Willför, S., Pranovich, A., Smeds, A.I., Virtanen, T.A.P., Maunu, SL., Verhoeff, F., Kiel, J.H., Hupa, M. 2014. Impact of torrefaction on the chemical structure of birch wood. Energy Fuels 28: 3863-3872.

Sluiter, A., Hames, B., Ruiz, R., Scarlata, C., Sluiter, J., Templeton, D. 2005. National Renewable Energy Laboratory, Standard Biomass Analytical Procedures. Available from: www.nrel.gov/biomass/analytical procedures.html.

Sun, R., Sun, X.F., Liu, G.Q., Fowler, P., Tomkinson, J. 2002. Structural and physicochemical characterization of hemicelluloses isolated by alkaline peroxide from barley straw. Polymer International 51(2):117-124.

Yi, Y.S., Cho, H.J., Heo, J.Y., Lee, Y.H. 2019. Effects of wood-derived biochar application on soil chemical properties and growth of Lettuce (Lactuca sativa L.). Korean Journal of Soil Science and Fertilizer 52(4): 457-466. 